\title{
PHYSICIAN-PATIENT COMMUNICATION: PERCEPTION AND PRACTICE AMONG DOCTORS WORKING IN TANTA UNIVERSITY OUTPATIENT CLINICS, EGYPT
}

\author{
By \\ Shalaby $\mathrm{SS}^{1}$, Saied $\mathrm{SM}^{1}$ and Zayed $\mathrm{HA}^{2}$ \\ ${ }^{1}$ Department of Public Health and Community Medicine, ${ }^{2}$ Department of Occupational \\ Medicine, Tanta University, Egypt
}

Corresponding author: Saied SM: shimaasaied@med.tanta.edu.eg

\begin{abstract}
Introduction: Effective physician-patient communication plays a crucial role in establishing a successful therapeutic outcome. Having good quality communication skills is vital for doctors to build up agreeable doctor-patient connection. In Egypt, the discipline of effective doctor-patient communication is still underestimated Aim of work: This study aimed to assess physicians' perception concerning the significance of effective physician-patient communication and to evaluate their actual practice and patient communication skills. Materials and methods: A cross-sectional study was conducted among physicians working at outpatient clinics at Tanta University Hospitals. Data collection was done using a self-administered questionnaire sheet conveyed to 275 randomly selected physicians working in different outpatient clinics. Physicians' perception concerning effective communication was assessed by means of self-assessment questions created by Samuel and Albert, and the level of physician-patient communication practice was assessed using the adapted Kalamazoo Checklist. Results: The study included 275 physicians; $48.6 \%$ of participants had highly perceived the significance of effective communication. 'Effective doctor-patient communication is highly associated with increased patient satisfaction' showed the highest perception among physicians $(94.5 \%)$. The medical curriculum followed by media and internet were the commonest sources of participants` information. About $41.8 \%$ of participant physicians had 'good' communication with a higher percentage among female doctors. Significant positive correlations were found between physicians' years of experience and communication skills practice competencies. Conclusion: About half of the physicians highly perceived the significance of effective doctor-patient communication and more than two-fifths of them had good doctor-patient communication skills. Enforcement of training courses concerning effective physician-patient communication is substantially recommended for both undergraduate students and graduated physicians.
\end{abstract}

Keywords: Physician-patient communication, Perception, Practice and Tanta University. 


\section{Introduction}

Effective as well as competent communication of doctors with their patients is fundamental for conveying high-quality patient care along with building a harmonious physicianpatient relationship which constitutes a core dimension of patient-centeredness (Shikawa et al., 2013 and Da Liu et al., 2016). Effective physicianpatient communication can be defined as the method in which a physician transfers information to a patient in a way that he understands the doctors instructions efficiently, supporting patients' self-management, managing of ambiguity and feelings, and helping decision making (Travaline et al., 2005; and Zolnierek and DiMatteo, 2009). Ineffective doctor-patient communication is challenging since it can result in non-adherence plus other health-related issues as the stress of paying for medical expenses (Meluch and Oglesby, 2015). Throughout the precedent years, patient-centeredness has been internationally discussed in all health care related fields (Baker, 2001). Patient-centered care is defined as clinical management given by medical experts that focuses on respecting and attending to patient's requirements, preferences, needs, and standards, instead of the physician's own plan (Breen et al., 2009). Physicians' communication skills affect a diversity of factors in clinical practice, and many studies revealed that effective doctorpatient communication increases patient satisfaction, patient understanding, recall, and compliance with treatment and health outcomes. Additionally, effective communication can also increase the physician's job-satisfaction, health, and well-being (Hu et al., 2016). Good communication is essential for both patients' and physicians' satisfaction, satisfied patients are less liable to malpractice complaints, and have better job satisfaction, a lesser amount of work-related stress, and diminished burnout (Harmon et al., 2006).

Studies have shown that excellent physician-patient communication [PPC] skills are related to patient health outcomes. Zolnierek and DiMatteo, 2009 in a meta-analysis study; stated that effective physician-patient communication has a positive significant correlation with patient adherence to treatment; they also found a considerable increase in the patients' adherence after doctors received communication skills training. Other studies established a 
positive association of physician-patient communication and patient satisfaction (Zandbelt et al., 2007; Clever et al., 2008; and Venetis et al., 2009), in addition to physical health outcomes (Michie et al., 2003). A meta-analysis incorporated 127 studies reported a significant association between patient adherence and communication training of doctors, furthermore, adherence and self-management can be improved if physicians are well trained to be better communicators (Zolnierek and DiMatteo, 2009). Communication skills have been revealed to be teachable and recognized as one of the six competencies by the Accreditation Council on Graduate Medical Education [ACGME] necessary for the effective practice of medicine (Batalden et al., 2002; and Baig et al., 2009).

Unfortunately, poor communication is the rule in public services in developing countries and the dominant paradigm is biomedicine (Unger et al., 2002). Medical education has to go beyond skills teaching to push physicians' responsiveness towards the patients' special experience (Stewart et al., 2000).

In Egypt, the discipline of effective PPC is still underestimated, which might be attributed to the increase in workload and the shortage of training on this significant topic (AbdelTawab and Roter, 2002). Although the incorporation of PPC into the medical curriculum as a separate course recently took place in the new competency-based medical education program, still all the previously graduated doctors were taught through the traditional curricula [which did not include a separate PPC course; it was just a topic in the medical ethics course].

Since the significance of physicianpatient communication has been commonly recognized and due to the paucity of Egyptian studies to investigate it; the conduction of the current research was urged.

\section{Aim of work}

To assess physicians' perception concerning the significance of effective physician-patient communication and to evaluate their actual practice and patient communication skills.

\section{Materials and methods}

Study design: It is a cross-sectional study

\section{Place and duration of the study:} The study was conducted at the outpatient clinics of Tanta University Hospitals; which provide secondary and tertiary healthcare services; it has 1962 
beds serving about 560000 patients per year. The study was held from October 2018 to January 2019.

The outpatient clinics include 23 clinics; 11 surgical and 12 medical ones. According to the hospital records, the total number of the residents and specialists working at the outpatient clinics was 650 physicians; 350 residents and 300 specialists (demonstrators and assistant lectures) (Tanta University Information and Statistics Unit; 2018).

Study sample: The sample size was calculated using Epi Info $^{\text {TM }}$ software created by WHO and CDC, Atlanta, Georgia, USA version 7.2.2.6.

The expected physicians' perception concerning the importance of successful doctor-patient communication was $46.5 \%$ based on a previous study (Salem and Abdelsalam, 2017) with a 5\% margin of error of and $95 \%$ confidence limit. The estimated sample size was 241 physicians. The sample was increased by $20 \%$ to increase accuracy and compensate for incompleteness, so 290 questionnaires were distributed to the studied physicians. The required sample was obtained using one stage stratified random sampling method. We divided the outpatient clinics into two strata; a medical stratum and a surgical one. The sample was randomly selected with proportional allocation between surgical and medical clinics including all physicians who were in job at the selected clinics based on the subsequent inclusion criteria: residents, demonstrators, and assistant lecturers working at different outpatient clinics of Tanta University Hospitals for more than 6 months. Exclusion criteria included: physicians who spent less than 6 months in the job and those who were on vacation during the study period. In the medical outpatient clinics, the total sample included 140 physicians while in the surgical ones; the total sample was 135 physicians.

\section{Study method:}

The data collection for the study was done using:

(I) A predesigned self-administered questionnaire which included two parts:

Part 1: Included socio-demographic data and occupational characteristics such as age, sex, residence, qualifications, and duration of work experience.

Part 2: To assess doctors' perception towards physician-patient communication, it included:

(a) Questions regarding previous information about PPC and its sources if any. 
(b) A validated self-assessment questionnaire developed by Samuel and Albert, 2006. It was submitted to participants in its original English language. It consisted of 10 statements answered on a 4 Likert scale from strongly agree to strongly disagree. Strongly agree and agree were considered 'high perception" for positive statements $[1,3,6,7,8,9,10]$, while disagree and strongly disagree represented high perception for negative statements $[2,4,5]$. A total perception score was calculated; high perception was considered when the total score was greater than the mean.

\section{(II) An observational checklist}

for the assessment of doctorpatient communication skills using Kalamazoo Essential Elements Communication Checklist (KEECC) [adapted], which is a reliable and valid tool for assessment of communication skills (Bayer, 2001). It uses global ratings on a 5 Likert scale from poor to excellent [ 1 = poor, 2 = fair, $3=$ good, $4=$ very good and $5=$ excellent] for both the 7 key competencies and 24 sub-competencies. It gives 7 key components of communication skills in clinical experiences; build the relationship, open the discussion, gather information, understand the patient's perspective, share information, reach an agreement, and provide closure. A total communication score was calculated by summation of responses to the 7 items with a maximum score as 120 ; where a higher score means better communication skills. A total score higher than the average (mean) was considered good communication (Salem and Abdelsalam, 2017). The observation was done by the researcher while the physician was not aware of being observed to avoid bias.

By the end of the data collection, 275 completed questionnaires were obtained [6 none returned and 9 incomplete questionnaires] with a response rate of $94.8 \%$.

\section{Consent}

Verbal consent was taken from all physicians who accepted to participate in the study preceding the distribution of the questionnaire sheet. No personal identifiers were included into the sheet and questionnaires were filled anonymously. Physicians were 
informed about the objective of the study, and that the collected data will be only utilized for research purposes.

\section{Ethical approval}

The study was approved by Tanta Faculty of Medicine Research Ethics Committee [REC]. Confidentiality of personal data and information was guaranteed.

\section{Data management}

The collected data were entered into Microsoft Excel spreadsheets, and analysis was done using SPSS 25.0 software (IBM Corp. Released 2017. IBM SPSS Statistics for Windows, Armonk, NY). Descriptive variables were expressed as frequency, percentages, and Mean \pm SD. Pearson chi-square was used to test for association between categorical variables. Binary logistic regression analysis was done to detect the independent predictors of both physicians' perception and communication practice. The level of significance was considered at $\mathrm{p}$-value $<0.05$.

\section{Results}

Table 1: Socio demographic and occupational characteristics of the studied physicians in relation to their communication grade based on Kalamazoo Essential Elements Communication Checklist.

\begin{tabular}{|c|c|c|c|c|c|}
\hline \multirow{3}{*}{$\begin{array}{c}\text { Socio-demographic } \\
\text { and Occupational } \\
\text { characters } \\
(\mathrm{No}=275)\end{array}$} & \multicolumn{2}{|c|}{$\begin{array}{l}\text { Physicians with poor } \\
\text { communication }\end{array}$} & \multicolumn{2}{|c|}{$\begin{array}{l}\text { Physicians with good } \\
\text { communication }\end{array}$} & \multirow{3}{*}{$\begin{array}{l}\chi^{2} \\
\mathbf{p}\end{array}$} \\
\hline & No & $\%$ & No & $\%$ & \\
\hline & 160 & 58.2 & 115 & 41.8 & \\
\hline \multicolumn{6}{|l|}{ Gender } \\
\hline Male & 81 & 50.6 & 41 & 35.7 & \multirow{2}{*}{$\begin{array}{c}6.08 \\
0.014 *\end{array}$} \\
\hline Female & 79 & 49.4 & 74 & 64.3 & \\
\hline \multicolumn{6}{|l|}{ Marital status } \\
\hline Unmarried $^{\mathrm{a}}$ & 105 & 65.6 & 60 & 52.2 & \multirow{2}{*}{$\begin{array}{r}5.04 \\
0.025 *\end{array}$} \\
\hline Married & 55 & 34.4 & 55 & 47.8 & \\
\hline Residence & & & & & \\
\hline
\end{tabular}




\begin{tabular}{|c|c|c|c|c|c|}
\hline Urban & 113 & 70.6 & 74 & 64.3 & \multirow{2}{*}{$\begin{array}{c}1.21 \\
0.271\end{array}$} \\
\hline Rural & 47 & 29.4 & 41 & 35.7 & \\
\hline \multicolumn{6}{|l|}{ Job } \\
\hline Resident & 150 & 93.8 & 50 & 43.5 & \multirow{2}{*}{$\begin{array}{c}85.3 \\
0.000 * *\end{array}$} \\
\hline Specialist & 10 & 6.3 & 65 & 56.5 & \\
\hline \multicolumn{6}{|c|}{ Outpatient clinics of work } \\
\hline Medical & 101 & 63.1 & 39 & 33.9 & \multirow{2}{*}{$\begin{array}{c}22.85 \\
0.000 * *\end{array}$} \\
\hline Surgical & 59 & 36.9 & 76 & 66.1 & \\
\hline \multicolumn{6}{|c|}{ Experience (in years) } \\
\hline $1<6$ years & 160 & 100.0 & 101 & 87.8 & \multirow{2}{*}{$\begin{array}{c}20.52 \\
0.000 * *\end{array}$} \\
\hline $6-12$ years & 0 & 0.0 & 14 & 12.2 & \\
\hline \multicolumn{6}{|c|}{ Do you have enough information regarding PPC? } \\
\hline Yes & 143 & 89.4 & 105 & 91.3 & \multirow{2}{*}{$\begin{array}{l}0.281 \\
0.596\end{array}$} \\
\hline NO & 17 & 10.6 & 10 & 8.7 & \\
\hline \multicolumn{6}{|c|}{ Had you attended any training course about PPC? } \\
\hline Yes & 38 & 23.8 & 58 & 50.4 & \multirow{2}{*}{$\begin{array}{c}20.97 \\
\mathbf{0 . 0 0 0} * *\end{array}$} \\
\hline NO & 122 & 76.3 & 57 & 49.6 & \\
\hline
\end{tabular}

*Statistically significant

a: Unmarried=Single, divorced and widowed
**: Highly statistically significant PPC: Physician patient communication

Table (1) showed that the study included 275 physicians; $153(55.6 \%)$ were females, and $122(44.4 \%)$ were males, their mean age was $27.9 \pm 2.8$ years. Near three-fourths of them $(72.7 \%)$ were residents. Totally, $41.8 \%$ of participant physicians had 'good' communication.

Among physician with 'good communication'; near two thirds $(64.3 \%)$ of them were females, and more than of their half (56.5\%) were specialists. Most of them $(91.3 \%)$ reported their information regarding PPC as enough, and half of them $(50.6 \%)$ had attended training courses, and the differences were statistically significant. All the low experienced physicians and none of the well-experienced ones had 'poor communication' with a statistically significant difference. 


\section{Table 2: Participants` perception about the significance of effective physician- patient communication.}

\begin{tabular}{|l|c|c|}
\hline \multicolumn{1}{|c|}{ Self-assessment perception statements } & $\begin{array}{c}\text { Participants with high } \\
\text { perception } \\
\text { (No=275) }\end{array}$ \\
\cline { 2 - 3 } & No & \% \\
\hline $\begin{array}{l}\text { - Good physician-patient communication has a positive impact on } \\
\text { health outcomes }\end{array}$ & 247 & 89.8 \\
\hline $\begin{array}{l}\text { - Improvements in doctors' communication skills are associated } \\
\text { with increases in the emotional distress of patients }\end{array}$ & 229 & 83.3 \\
\hline $\begin{array}{l}\text { - Better doctor-patient communication is associated with better } \\
\text { control of chronic diseases }\end{array}$ & 245 & 89.1 \\
\hline $\begin{array}{l}\text { - Patient-centered visits are associated with more diagnostic tests } \\
\text { and referrals in the subsequent months }\end{array}$ & 157 & 57.1 \\
\hline $\begin{array}{l}\text { - Low compliance with prescribed medical interventions is } \\
\text { associated with reduced medical costs }\end{array}$ & 212 & 77.1 \\
\hline $\begin{array}{l}\text { - The doctors' attitudes towards their patients, their ability to elicit } \\
\text { and respect the patients' concerns, the demonstration of empathy } \\
\text { and the development of patient trust are the key determinants of } \\
\text { good compliance with medical interventions. }\end{array}$ & 229 & 83.3 \\
\hline $\begin{array}{l}\text { - Effective doctor-patient communication is highly associated with } \\
\text { increased patient satisfaction. }\end{array}$ & 260 & 94.5 \\
\hline $\begin{array}{l}\text { - Doctors' satisfaction with their professional life is associated with } \\
\text { greater patient trust and confidence. }\end{array}$ & 252 & 91.6 \\
\hline $\begin{array}{l}\text { - Communication problems are important factors in medical } \\
\text { litigation. }\end{array}$ & 200 & 72.7 \\
\hline $\begin{array}{l}\text { - Adequate research has been done to evaluate doctor-patient } \\
\text { relationship and doctor-patient communications }\end{array}$ & 220 & 80.0 \\
\hline Total perception & 134 & \\
\hline
\end{tabular}

Table (2) showed that high perception regarding the importance of effective physician-patient communication was totally revealed among $48.6 \%$ of the physicians. 'Effective doctor-patient communication is highly associated with increased patient satisfaction', 'Doctors' satisfaction with their professional life is associated with greater patient trust and confidence', and 'Good physician-patient communication has a positive impact on health outcomes' were the most commonly highly perceived items $(94.5 \%, 91.6 \%$ and $89.8 \%$; respectively). 
Table 3: Logistic regression analysis of factors affecting perception and practice of doctor-patient communication

\begin{tabular}{|c|c|c|c|c|c|}
\hline \multicolumn{2}{|r|}{ Variables } & $\boldsymbol{\beta}$ & S.E. & Wald & $\mathbf{p}$ \\
\hline \multirow{4}{*}{ } & Work's department & $-0.78-$ & 0.28 & 7.62 & $0.006 *$ \\
\hline & Gender & $-0.27-$ & 0.28 & 0.94 & 0.332 \\
\hline & Experience duration / years & $-1.6-$ & 0.37 & 18.67 & $0.000 * *$ \\
\hline & Previous training course & 0.58 & 0.29 & 3.85 & 0.050 \\
\hline \multirow{4}{*}{ D } & Work's department & 0.79 & 0.310 & 6.39 & 0.011* \\
\hline & Gender & $-0.51-$ & 0.312 & 2.65 & 0.104 \\
\hline & Experience duration / years & 2.63 & 0.466 & 31.86 & $0.000 * *$ \\
\hline & Previous training course & $-0.61-$ & 0.320 & 3.57 & 0.059 \\
\hline
\end{tabular}

S.E: Standard error

**: Highly statistically significant

*: Statistically significant

Table (3) showed that binary logistic regression revealed that the significant independent predictors of both physicians' perception and communication practice were the work's department and experience duration in years.

Table 4: Correlation between physicians' years of experience and communication skills practice competencies.

\begin{tabular}{|l|l|c|}
\hline \multicolumn{3}{|c|}{ Experience duration / years } \\
\hline \multicolumn{2}{|c|}{ Pearson Correlation } & Sig. (2-tailed) \\
\hline Communication skills competencies & $\mathbf{0 . 4 2 1} * *$ & 0.000 \\
\hline Building a relationship & $\mathbf{0 . 1 7 8} * *$ & 0.003 \\
\hline Opening the discussion & $\mathbf{0 . 3 1 2} * *$ & 0.000 \\
\hline Gathering information & $\mathbf{0 . 6 4 6} * *$ & 0.000 \\
\hline Understanding the patient's perspective & $\mathbf{0 . 3 8 7 * *}$ & 0.000 \\
\hline Sharing information & $\mathbf{0 . 6 6 8} * *$ & 0.000 \\
\hline Reaching agreement & $\mathbf{0 . 5 0 8 * *}$ & 0.000 \\
\hline Providing Closure & $\mathbf{0 . 6 4 9 * *}$ & 0.000 \\
\hline Total checklist & & \\
\hline
\end{tabular}

**Correlation is significant at the 0.01 level (2-tailed).

**: Highly statistically significant 
Table (4) revealed significant positive correlations between physicians' years of experience and communication skills practice competencies [total score and individual competencies, and the strongest correlation was between experience with 'Reaching agreement' competency and the total communication score ( $\mathrm{r}=$ $0.668,0.649, \mathrm{p}=0.000$; respectively).

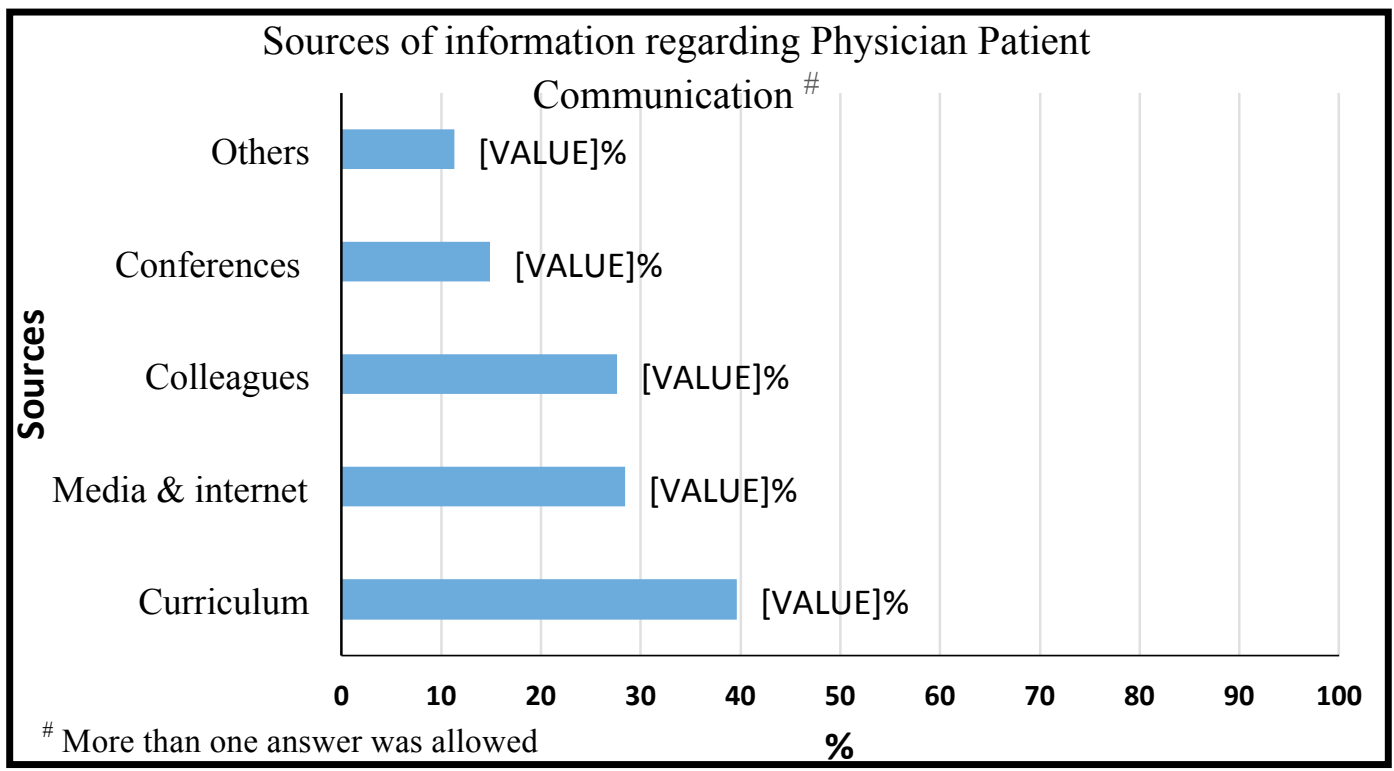

Figure 1: Sources of information regarding Physician-Patient Communication

Figure (1) revealed that near two fifths (39.6\%) of the participants reported their medical curriculum as the source of their PPC information, followed by media and internet (28.4\%), while the least reported source was conferences (14.9\%).

\section{Discussion}

Effective physician-patient communication is the heart and art of medicine and a crucial component in health care delivery. However- to some extent- it remains a disregarded ingredient in clinical medicine. As this important issue has not been commonly addressed; this study was conducted aiming to detect the physicians' perception regarding effective communication and to measure their practice of communication skills. 
The current study revealed the effect of gender on communication practices as a significantly higher percentage of good communicators were females (Table 1). In accordance with literature findings, female physicians showed superior communication attitude and behaviors. This may be explained by the emotional built and the more patient and sympathetic nature of females. Also, evidence revealed that female doctors are skilled in rapport building through positive talks and reassurance (Löffler et al., 2016 and Salem and Abdelsalam, 2017). However, other studies concluded that gender has no effect on communication practice with the patients (Brink et al., 2002; Ajay et al., 2010; and Laura et al., 2013).

Surprisingly, most of the participants who were classified as having poor communication reported that they have enough information regarding doctorpatient communication (Table 1). This may be attributed to that physicians may frequently overestimate their ability to communicate in interpersonal interactions (Belasen and Belasen, 2018).

In the present work, a significantly higher percentage of physicians with good communication skills reported attendance of training courses
(Table 1). This is supported by the fact that communication skills are teachable as doctors are not born with tremendous communication skills, but training improves doctorpatient communication. So future procedures for providing doctor-patient communication training in medical colleges should be considered (Ha and Longnecker, 2010; and Da Liu et al., 2016).

The present study revealed that the total perception of the importance of good physician-patient communication was $48.6 \%$ (Table 2), which is slightly higher than the results reported by Salem and Abdelsalam, 2017 who detected that the total perception was $46.5 \%$ among physicians working in a governmental hospital at Sharkia governorate, though this perception is considered low. This may be explained by an inappropriate training of most of Egyptian undergraduates and postgraduates on the patient-centered care in the previous traditional curriculum, but now in the new competency-based medical education programmes, better chances are made available for the new graduates regarding interviewing and physician-patient communication skills. Unfortunately, few studies focused on physicians perception of 
effective doctor-patient communication as research and mostly focus paid attention on the patient perspective, rather than both physician and patient perspective (Jahng et al., 2005).

In the current study, most of the participants showed high perception regarding "Doctors' satisfaction with their professional life" is associated with greater patient trust and confidence' (Table 2). This was in accordance with Grembowski et al., 2005; on their study on managed care, physician job satisfaction and the quality of primary care ; they highlighted that effective communication together with patientcentered care were related to increased physicians' satisfaction with their professional life.

Most of the participants highly perceived that "Good physician-patient communication has a positive impact on health outcomes" (Table 2). Similarly, Singh, 2016 reported that effective doctor-patient communication is linked to enhanced health outcomes, improved cooperation and elevated satisfaction of both physicians and patients.

Physicians experience was found to be a significant predictor of their perception towards the effectiveness of the good doctor-patient communication (Table 3); which was in agreement with
Geurt et al., 2011 in their explorative study in general practice who considered experience as a relevant context factor.

More experienced physicians appeared to know what they were questioning for, used fewer questions, applied the skill 'Structuring' more easily, and without losing main data (Geurt et al., 2011). The present study revealed significant positive correlations between physicians' years of experience and communication skills practice competencies (Table 4); this was in accordance with Jager et al., 2011 who detected adequate communication patterns in experienced physicians. Also, this was in line with Geurt et al., 2011 who reported the importance of experience in good communication.

As a considerable percentage of the study participants considered the medical curriculum as the main information source regarding physician-patient communication (Figure 1); therefore, the inclusion of this issue in new curricula became necessary. Numerous medical colleges already incorporated doctor-patient communication skill tuition into medical curricula (Sijstermans et al., 2007; Carvalho et al., 2010; and Loue et al., 2015).

\section{Conclusion and recommendations:}

In conclusion, near half of the 
studied physicians highly perceived the significance of effective doctorpatient communication, more than twofifths of them had good doctor-patient communication skills, and female doctors showed a higher rate of good communication skills. A high percentage of the participants reported curriculum as the most important source for their information; so medical educational strategies for providing training on effective doctor-patient communication for both under and postgraduates are needed, also pre-employment and inservice training of the physicians on the essential key communication skills competencies should be addressed.

Limitations of the study: Single physician observation was taken which may not reflect the actual physician`s practice in all situations. Scare Egyptian studies in the same field did not allow a detailed discussion of the results.

\section{Conflict of interests}

None to declare.

\section{Funding}

\section{None}

\section{Acknowledgment}

The authors express their deepest thanks to all physicians who participated in this study.

\section{References}

1. Abdel-Tawab N and Roter D (2002): The relevance of client-centered communication to family planning settings in developing countries: lessons from the Egyptian experience. Soc Sci Med; 54 (9):1357-68.

2. Ajay KS, Veerendra S and Nira K (2010): Doctor-patient communication: An important but often ignored aspect in clinical medicine. JIACM; 11 (3): 208-11.

3. Baig LA, Violato C and Crutcher RA (2009): Assessing clinical communication skills in physicians: are the skills contexts specific or generalizable. BMC Med Educ; 9 (1):22.

4. Baker A (2001): Crossing the quality chasm: a new health system for the 21 st century. BMJ; 17; 323 (7322):1192.

5. Batalden P, Leach D, Swing S, Dreyfus H and Dreyfus S (2002): General competencies and accreditation in graduate medical education. Health Aff; 21 (5):103-11.

6. Bayer-Fetzer (2001): Essential elements of communication in medical encounters. The Kalamazoo Consensus Statement. Acad Med; 76:390-3.

7. Belasen A and Belasen AT (2018): Doctorpatient communication: a review and a rationale for using an assessment framework. J Health Organ Manag; 8; 32 (7):891-907.

8. Breen GM, Wan TT, Zhang NJ, Marathe SS, Seblega BK, et al. (2009): Improving doctor-patient communication: examining innovative modalities vis-à-vis effective patient-centric care management technology. $\mathrm{J}$ Med Syst; 33 (2): 155-62.

9. Brink MA, Dulmen S, Messerli RV and Bensing J (2002): Do gender-dyads have different communication patterns? A comparative study in Western-European general practices. Patient Educ Couns; 48 (3): 253-64.

10. Carvalho IP, Ribeiro-Silva R, Pais VG, Figueiredo-Braga M, Castro-Vale I, et al. (2010): Teaching doctor-patient communication-a 
proposal in practice. Acta Med Port; 23 (3):52732.

11. Clever SL, Jin L, Levinson W and Meltzer DO (2008): Does doctor-patient communication affect patient satisfaction with hospital care? Results of an analysis with a novel instrumental variable. Health Serv Res; 43 (5):1505-19.

12. Da Liu, Longwen $\mathrm{Xu}$, Zhaoyang Yin, Yayu Huang and $\mathrm{Li} \mathrm{Xu}$ (2016): Preliminary Assessment for Attitudes of Medical Students to Doctor-Patient Communication. SJEDU; 4 (3): 113-17

13. Geurt E, Sandra D, Chris W, Cees V and Anneke $\mathrm{K}$ (2011): Identifying context factors explaining physician's low performance in communication assessment: An explorative study in general practice. BMC Family; 12:138.

14. Grembowski D, Paschane D, Diehr P, Katon W, Martin D, et al.(2005): Managed care, physician job satisfaction and the quality of primary care. J Gen Intern Med; 20: 271-7.

15. Ha JF and Longnecker N (2010): Doctor-patient communication: a review. Ochsner J; 10 (1):3843.

16. Harmon G, Lefante $\mathrm{J}$ and Krousel-Wood M (2006): Overcoming barriers: the role of providers in improving patient adherence to antihypertensive medications. Curr Opin Cardiol; 21 (4):310-5.

17. Hu W, Song $\mathrm{Y}$, Zhong $\mathrm{X}$, Feng J, Wang $\mathrm{P}$, et al. (2016): improving doctor-patient communication: content validity examination of a novel urinary system-simulating physical model. Patient Prefer Adherence; 10:2519.

18. Jager $\mathrm{M}$, Schuling $\mathrm{J}$, Pols $\mathrm{J}$ and Berenst $\mathrm{J}$ (2011): Differences in communication skills between trainee and experienced GPs. Huisarts Wet; 54:478-82.

19. Jahng KH, Martin LR, Golin CE and Di Matteo MR (2005): Preferences for medical collaboration: patient-physician congruence and patient outcomes. Patient Educ Couns; 57 (3):308-14.
20. Laura J, Karen B, Yvonne B, Catherine H and Martin B (2013): Effect of physicians' gender on communication and consultation length: a systematic review and meta-analysis. J Health Serv Res Policy; 18 (4): 242-8.

21. Löffler-Stastka H, Seitz T, Billeth S, Pastner B, Preusche I, et al. (2016): Significance of gender in the attitude towards doctor-patient communication in medical students and physicians. Wien Klin Wochenschr; 128 (1718):663-8.

22. Loue S, Wilson-Delfosse A and Limbach K (2015): Identifying gaps in the cultural competence/sensitivity components of an undergraduate medical school curriculum: a needs assessment. J Immigr Minor Health; 17 (5):1412-9.

23. Meluch AL and Oglesby WH (2015): Physician-patient communication regarding patients' healthcare costs in the US: A systematic review of the literature. Journal of Communication in Healthcare; 8 (2):151-60.

24. Michie S, Miles J and Weinman J ( 2003): Patient-centredness in chronic illness: what is it and does it matter? Patient Educ Couns; 51 (3):197-206.

25. Salem GM and Abdelsalam AE (2017): Doctor- patient communication, what is the situation? An intervention study at a selected governmental hospital at Sharkia governorate. JHIPH; 47 (1):22-8.

26. Samuel YS and Albert L (2006): Communication skills and doctor patient relationship. Med Bull; 11 (3): 7-9.

27. Shikawa H, Hashimoto H and Kiuchi T (2013): The evolving concept of "patient-centeredness" in patient-physician communication research. Soc Sci Med; 96: 147-53.

28. Sijstermans R, Jaspers MW, Bloemendaal PM and Schoonderwaldt EM (2007): Training interphysician communication using the Dynamic Patient Simulator. Int J Med Inform; 76 (56):336-43. 
29. Singh M (2016): Communication as a bridge to build a sound doctor-patient/parent relationship. Indian J Pediatr; 83 (1):33-7.

30. Stewart M, Brown JB, Donner A, McWhinney IR, Oates J, et al. (2000): The impact of patient centered care on outcomes. J Fam Pract; 49 (9):796-804.

31. Tanta University Information and Statistics Unit (2018): Annual records of physician numbers and patient admission rates.

32. Travaline JM, Ruchinskas $\mathrm{R}$ and D'Alonzo Jr GE (2005): Patient-physician communication: why and how. J Am Osteopath Assoc; 105(1):13.

33. Unger JP, Van Dormael M, Criel B, Van der Vennet J and De Munck P (2002): A plea for an initiative to strengthen family medicine in public health care services of developing countries. Int J Health Serv; 32 (4):799-815.

34. Venetis MK, Robinson JD, Turkiewicz KL and Allen M (2009): An evidence base for patientcentered cancer care: a meta-analysis of studies of observed communication between cancer specialists and their patients. Patient Educ Couns; 77 (3):379-83.

35. Zandbelt LC, Smets EM, Oort FJ, Godfried MH and de Haes HC (2007): Medical specialists' patient-centered communication and patientreported outcomes. Med Care; 45 (4):330-39.

36. Zolnierek KB and DiMatteo MR (2009): Physician communication and patient adherence to treatment: a meta-analysis. Med Care; 47(8):826-34 